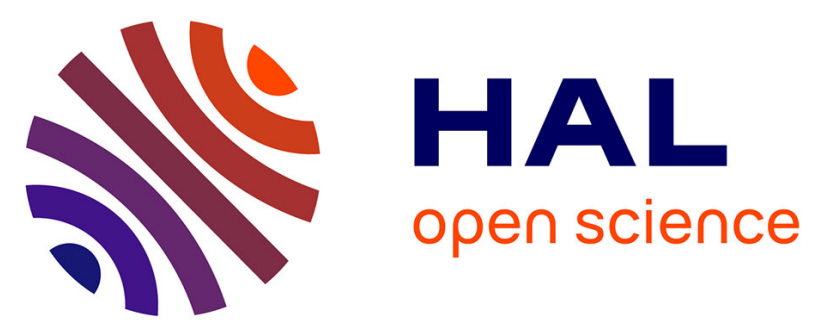

\title{
Screening of superior fiber-quality-traits among wild accessions of Bambusa balcooa: efficient and non-invasive evaluation of fiber developmental stages
}

Samik Bhattacharya, Jayadri S. Ghosh, Dipak K. Sahoo, Nrisingha Dey, Amita Pal

\section{To cite this version:}

Samik Bhattacharya, Jayadri S. Ghosh, Dipak K. Sahoo, Nrisingha Dey, Amita Pal. Screening of superior fiber-quality-traits among wild accessions of Bambusa balcooa: efficient and non-invasive evaluation of fiber developmental stages. Annals of Forest Science, 2010, 67 (6), 10.1051/forest/2010024 . hal-00883613

\section{HAL Id: hal-00883613 \\ https://hal.science/hal-00883613}

Submitted on 1 Jan 2010

HAL is a multi-disciplinary open access archive for the deposit and dissemination of scientific research documents, whether they are published or not. The documents may come from teaching and research institutions in France or abroad, or from public or private research centers.
L'archive ouverte pluridisciplinaire HAL, est destinée au dépôt et à la diffusion de documents scientifiques de niveau recherche, publiés ou non, émanant des établissements d'enseignement et de recherche français ou étrangers, des laboratoires publics ou privés. 


\title{
Screening of superior fiber-quality-traits among wild accessions of Bambusa balcooa: efficient and non-invasive evaluation of fiber developmental stages
}

\author{
Samik Bhattacharya ${ }^{1,3 *}$, Jayadri S. GHOSH ${ }^{1,2 *}$, Dipak K. SAHOO ${ }^{2}$, Nrisingha DeY $^{2}$, Amita PAL $^{1 * *}$ \\ ${ }^{1}$ Plant Molecular and Cellular Genetics, Bose Institute, P1/12 CIT Scheme VII M, Kolkata-700054, India \\ ${ }^{2}$ Department of Gene Function and Regulation, Institute of Life Sciences, Nalco Square, Chandrasekharpur, Bhubaneswar-751023, Orissa, India \\ ${ }^{3}$ Max Planck Institute for Chemical Ecology, Department of Molecular Ecology, Hans-Knöll-Straße 8, 07745 Jena, Germany
}

(Received 25 May 2009; accepted 19 August 2009)

Keywords:

Bambusa balcooa /

cellulose /

fiber /

lignin /

CLSM

\begin{abstract}
- The search for alternative fiber resources is receiving worldwide attention for the potential role of these fibers in climate and forest restoration. Among bamboos, Bambusa balcooa is generally preferred for industrial use due to its rapid growth, excellent flexibility and tensile strength. The aim of this study is to establish a non-invasive and efficient method of screening superior fiber quality from the wild gene pool of B. balcooa.

- Anatomical features of B. balcooa internodes were revealed by light microscopy. Confocal laser scanning microscopy (CLSM) was used to study fiber developmental stages in emerging branches using the intrinsic fluorescence properties of lignin and chlorophyll. Physical properties of $B$. balcooa fibers from different gene pools were studied, and biochemical estimations of lignin and cellulose contents were performed. CLSM-based semi-quantitative in situ estimations of cellulose and lignin contents in fiber bundles were performed using orthochromatic Congo red (CR) and acridine orange (AO) labeling, respectively.

- Fibers isolated from representative accessions of locations 3 and 4 showed the highest cellulose contents and superior physical properties. The results obtained from biochemical analyses of cellulose and lignin contents of fiber bundles among the accessions correlate significantly with CR and AO fluorescence values using non-invasive methods. A CLSM-based study demonstrated the possibility of differentiating stages of fiber development with autofluorescent markers of lignin and lignin precursors that would help to define stages of fiber development and maturation in bamboo effectively, which is a prerequisite for understanding the mechanism of fiber development at the molecular level in bamboo.

- A CLSM-based cellulose and lignin assay is a non-invasive method, exploited for the first time for genetic diversity screening in a wild gene pool. This protocol would also be useful for rapid resource screening for various commercial purposes.
\end{abstract}

\section{INTRODUCTION}

Bamboos, the giant members of the grass family, are often considered "green gold" for their economic importance and multipurpose utilization from "cradle to coffin." During the last two decades, bamboo has gained significant attention as a non-wood fiber resource. Bamboo fiber-based panels and boards are hard, durable and prove to be a promising substitute for hard woods in merchandise production. Moreover, bamboo fibers yield paper with a high tear index and almost the same

\footnotetext{
* These authors contributed equally to this work.

** Corresponding author:

amita@bic.boseinst.ernet.in; amita_pal@yahoo.com
}

strain strength as paper made from wood (FAO, 1997). Bambusa balcooa is an abundant tropical species and is recognized as a priority bamboo species among eighteen other globally distributed bamboo species (Das et al., 2005). In addition, with its rapid rate of regeneration, it can quickly restore forest flora and the pre-existing environmental milieu. B. balcooa is generally preferred for construction purposes and fiber-based mat board and panel fabrication (Ganapathy, 1997); primarily due to its mechanical strength, it is also used to produce quality paper pulp (Das et al., 2005).

Unfortunately, comprehensive investigations toward proper evaluation of non-wood fiber sources of bamboo are limited (Liese, 1992; Parameswaran and Liese, 1976; Xu et al., 2006). 
Table I. Geographical locations of B. balcooa collection sites with representative accession numbers in West-Bengal, India.

\begin{tabular}{cccccc}
\hline Location number & Representative accession number & Place of collection & Latitude & Longitude & Altitude (m) \\
\hline 1 & $\mathrm{SB} / \mathrm{SIB} / 02 / 016$ & Sibpur & $22^{\circ} 34^{\prime} \mathrm{N}$ & $88^{\circ} 19^{\prime} \mathrm{E}$ & 10.0 \\
2 & $\mathrm{SB} / \mathrm{SAR} / 02 / 018$ & Saradapally & $22^{\circ} 56^{\prime} \mathrm{N}$ & $88^{\circ} 11^{\prime} \mathrm{E}$ & 12.0 \\
3 & $\mathrm{SB} / \mathrm{BHA} / 03 / 023$ & Bhadreswar & $22^{\circ} 49^{\prime} \mathrm{N}$ & $88^{\circ} 21^{\prime} \mathrm{E}$ & 11.6 \\
4 & $\mathrm{SB} / \mathrm{DRA} / 03 / 025$ & Dighra 1 & $22^{\circ} 54^{\prime} \mathrm{N}$ & $88^{\circ} 26^{\prime} \mathrm{E}$ & 11.0 \\
5 & $\mathrm{SB} / \mathrm{DGA} / 03 / 037$ & Dighra 2 & $22^{\circ} 54^{\prime} \mathrm{N}$ & $88^{\circ} 06^{\prime} \mathrm{E}$ & 11.0 \\
6 & $\mathrm{SB} / \mathrm{SRE} / \mathrm{O} 3 / 046$ & Srerampur & $22^{\circ} 53^{\prime} \mathrm{N}$ & $88^{\circ} 24^{\prime} \mathrm{E}$ & 14.2 \\
7 & $\mathrm{SB} / \mathrm{SIN} / 03 / 056$ & Singur & $22^{\circ} 48^{\prime} \mathrm{N}$ & $88^{\circ} 13^{\prime} \mathrm{E}$ & 13.0 \\
8 & $\mathrm{SB} / \mathrm{MEM} / 03 / 067$ & Memari & $23^{\circ} 11^{\prime} \mathrm{N}$ & $88^{\circ} 7^{\prime} \mathrm{E}$ & 24.0 \\
9 & $\mathrm{SB} / \mathrm{MAN} / 04 / 082$ & Mankundu & $22^{\circ} 55^{\prime} \mathrm{N}$ & $88^{\circ} 24^{\prime} \mathrm{E}$ & 18.0 \\
10 & $\mathrm{SB} / \mathrm{RIS} / 04 / 087$ & Rishrah & $22^{\circ} 47^{\prime} \mathrm{N}$ & $88^{\circ} 22^{\prime} \mathrm{E}$ & 13.8 \\
11 & $\mathrm{SB} / \mathrm{DHI} / 04 / 094$ & Dhitara & $22^{\circ} 55^{\prime} \mathrm{N}$ & $88^{\circ} 18^{\prime} \mathrm{E}$ & 12.0 \\
12 & $\mathrm{SB} / \mathrm{CHU} / 04 / 104$ & Chinsura & $22^{\circ} 58^{\prime} \mathrm{N}$ & $88^{\circ} 25^{\prime} \mathrm{E}$ & 18.0 \\
\hline
\end{tabular}

Therefore, in the present investigation, the fiber qualities of the wild gene pool of $B$. balcooa were analyzed using a rapid, simpler technique. A confocal microscopic method was also employed to identify the ideal developmental stages for fiber harvest. Our objective was to develop a rapid method for fiber quality assessment, which is essential for successful genetic diversity screening from the wild gene pool. Such protocols would also be useful for the judicious selection of raw bamboo materials for various commercial applications.

In this investigation, we analyzed physical and chemical properties of fibers from representative accessions of $B$. balcooa from 12 locations. Bright field and Confocal Laser Scanning Microscopy (CLSM) were employed in a coherent manner to reveal detailed anatomical features of $B$. balcooa to understand the ontogeny of fiber sheaths from parenchymatous pith cells. A comparative study was performed among accessions of $B$. balcooa to estimate cellulose and lignin contents in sections of lignified fiber bundles in situ using suitable CLSM-based software following orthochromatic labeling with Congo red (CR) and acridine orange (AO). The results were correlated with results obtained from a biochemical assay of cellulose and lignin contents. This study provided a way to efficiently screen superior accessions from wild $B$. balcooa resources. The techniques employed here could be extended to other economically important bamboo species as well as to other non-wood plant sources for fiber quality assessment.

\section{MATERIALS AND METHODS}

\subsection{Plant material}

Wild habitats of Bambusa balcooa (Roxb.) across 12 locations of West Bengal in India were surveyed (Tab. I). Each location was represented by five randomly selected clumps (culms growing together). Five adult culms from each clump ( 25 accessions in total) of all selected locations were independently sampled $(25 \times 12=300$ samples) for fiber isolation. The middle segment of the 5 th internode was used as the experimental material for studying fiber characteristics, as it represents the average length of all internodes in a branch (Ververis et al., 2004).

\subsection{Isolation of fiber cells from the 5 th internodes of $B$. balcooa}

Small slivers were prepared by macerating internodes with $10 \mathrm{~mL}$ of $67 \%$ nitric acid, boiling the samples in a water bath for $10 \mathrm{~min}$ and washing samples thoroughly in distilled water (Ogbonnaya et al., 1997). Individual fiber cells were mechanically isolated from macerated fiber bundles using a plastic churner, using appropriate care to avoid any damage. Measurements for fiber diameter, cell wall thickness and lumen diameter (fiber diameter: cell wall thickness) were performed for 25 fiber cells independently isolated from each internode. Altogether, 625 individual fiber cells $(25$ replications $\times 5$ culms $\times 5$ clumps) from each of the 12 locations $(25$ accessions per location) were characterized for 3 physical parameters. The following equations were used to derive these physical traits: slenderness ratio $=$ fiber length/fiber diameter; flexibility coefficient $=($ fiber lumen diameter/fiber diameter $) \times 100$; and Runkel ratio $=(2 \mathrm{X}$ fiber cell wall thickness)/lumen diameter (Ogbonnaya et al., 1997; Saikia et al., 1997).

\subsection{Light microscopic study of culm anatomy}

Thin transverse hand-sections (approx. $80 \mu \mathrm{M}$ thick) of the culm internodes were stained with Safranin O and Light green, followed by glycerol mounting to visualize the tissue organization. Isolated fiber cells were placed on a glass slide and stained with methylene blue solution $(0.5 \%)$ and glycerin $(1: 1 \mathrm{v} / \mathrm{v})$. The length, diameter, fiber wall thickness and fiber lumen diameter of isolated fiber cells ( $n=625$ /location) were recorded using a light microscope and a standardized ocular micrometer.

\subsection{Estimation of $\alpha$-cellulose and lignin contents}

The $\alpha$-cellulose content was estimated using a colorimetric method based on anthrone reagent (Updegraff, 1969). Approximately $1.0 \mathrm{~g}$ of internode tissues were crushed, mixed with $3 \mathrm{ml}$ of nitric acid and acetic acid solution $(1: 8 \mathrm{v} / \mathrm{v})$ and refluxed in boiling water for $30 \mathrm{~min}$. Lignin, hemicellulose and xylosans were removed by successive washing followed by centrifugation. The resulting pellet was dissolved in $67 \%$ sulphuric acid (v/v), mixed with chilled anthrone reagent (HiMedia Laboratories, India), incubated for $20 \mathrm{~min}$ in boiling water followed by a quick chilling on ice and incubated again 
at ambient temperature for $10 \mathrm{~min}$ prior to assaying at $620 \mathrm{~nm}$ in a spectrophotometer (Beckman-Coulter, DU-520). $\alpha$-cellulose content was estimated from the standard curve of a cellulose standard (Merck, Germany) and was expressed as the gram percentage of fiber dry weight (DW).

Acid-insoluble lignin content (Klason lignin) was determined according to the standard of the American Society for Testing and Materials (ASTM, 1996). Three accessions were randomly chosen for estimation of $\alpha$-cellulose and lignin contents for each location.

\subsection{Confocal laser scanning microscopy (CLSM) of cell wall components}

Fluorescence images of thin transverse sections of different (2nd, 4th and 5th) internodes of B. balcooa were captured using CLSM (TCS SP5; Leica, D-68165 Mannheim, Germany) and LAS AF (Leica Application Suite Advanced Fluorescence, 1.8.1) build 1390 software under an HCX PL APO objective (10X/NA 0.40) with a confocal pinhole set at "Airy" 5.50 and zoomed to a factor of $1.4 \mathrm{X}$ for improved 8-bit resolution. Autofluorescence of lignin and lignin precursor molecules were measured with a pinhole size of 5.5 airy disc to obtain the best signal from the samples at the lowest molecule concentrations. For exciting bamboo sections, a 405-nm Diode laser $(50 \mathrm{~mW})$ was used, with an emission bandwidth ranging from 440 $460 \mathrm{~nm}$ (detector gain set at $1250 \mathrm{~V}$ ) for blue fluorescence in a photomultiplier tube detector (PMT I) and between 525-535 nm (detector gain set at 1045 V) for green fluorescence in PMT II. Simultaneously, a $40 \%$ argon laser with AOTF for $458 \mathrm{~nm}(20 \mathrm{~mW})$ was used to excite same sections, and red fluorescence emissions were collected between 640 and $700 \mathrm{~nm}$ with the PMT detector gain set at $100 \mathrm{~V}$ after passage through a triple dichroite TD 458/514/594. To optimize image quality, the offset was adjusted for a maximum range of fluorescence from 0 to 255 and zero mean amplitude for a non-fluorescing region in the field. To observe anatomical changes concomitant with fiber sheath development during culm maturation, sections of internodal regions at various stages were exposed under CLSM, and autofluorescence images of lignin, lignin precursors (such as ferulic acid) and other cell wall components were acquired at various excitation and emission ranges. Bright field and superimposed images of the sections were also taken for detailed comparisons.

\subsection{Congo red staining of internodal sections}

Thin transverse 5th internodal sections of B. balcooa from representative accessions of 12 locations were incubated in a $0.2 \%$ aqueous solution of Congo red (CR) (Merck, Darmstadt, Germany) overnight in the dark (Hommel et al., 2008). The samples were then washed with deionized water, and images were acquired using CLSM with a confocal pinhole set at 'Airy' 1.0. A 30\% Argon laser with AOTF for $514 \mathrm{~nm}(20 \mathrm{~mW})$ was used for exciting CR-labeled samples, and red fluorescence emissions were acquired between 560 and $800 \mathrm{~nm}$ with the PMT detector gain set at $1100 \mathrm{~V}$. Fluorescence was recorded after passage through a triple dichroite 458/514/594. After image acquisition, CR fluorescence intensities of fiber sheaths of all samples were quantified by LAS AF software, following instructions provided by Leica Microsystems, Germany. CaliBRITE ${ }^{\mathrm{TM}} 3$ fluorescent beads for three colors (Cat\# 340486, BD Biosciences, Singapore) were used as internal standards, and images were captured using a HCX PL APO objective (63X/NA 1.40) under the above stated conditions. Fluorescence intensities were measured at different time intervals.

\subsection{Acridine orange staining of internodal sections and isolated fibers}

Thin transverse 5th internodal sections and isolated B. balcooa fibers from representative accessions of 12 locations were treated with $10^{-6} \mathrm{M}$ acridine orange (AO) for orthochromatic labeling in the dark with gentle shaking for $1 \mathrm{~h}$. The samples were then washed with deionized water, and images were acquired using CLSM with a confocal pinhole set at "Airy" 1.0. A 30\% Argon laser with AOTF for $488 \mathrm{~nm}$ (20 mW) was used for exciting AO-labeled samples, and green fluorescence emissions were collected between 515 and $545 \mathrm{~nm}$ with the PMT detector gain set at $830 \mathrm{~V}$. Fluorescence was recorded after passage through a double dichroite 488/561, and image quality was optimized by adjusting the offset for a maximum range. After image acquisition, AO fluorescence intensities of isolated fibers and fiber sheaths of all samples were quantified. CaliBRITE ${ }^{\mathrm{TM}} 3$ fluorescent beads were used as internal standards.

\subsection{Statistical analysis}

Statistical analyses were performed using SPSS Statistics (ver. 17.0) software. The bivariate Pearson correlation coefficient (with two-tailed significance test) was computed between the fluorescence intensity data (obtained following CR and AO staining of cellulose and lignin, respectively) and the corresponding biochemical estimations.

\section{RESULTS AND DISCUSSION}

\subsection{A microscopic study of $B$. balcooa culm anatomy}

Transverse sections through B. balcooa internodes revealed the presence of numerous collateral vascular bundles surrounded by parenchymatous tissue with a central hollow region. Parenchymatous cells are small in the outer culm wall and become larger, especially in length, toward the inner part, becoming smaller again near the pith cavity.

Fibers are generally long, slender cells and are tapered at both ends; they are grouped together in sheaths or bundles. Several reports have dealt with the influence of bamboo fiber's length on culm strength and its pulping properties (Espiloy, 1987; Widjaja and Risyad, 1987). Fibers are composed of sclerenchymatous tissue and occupy approximately $40 \%$ of the culm volume. Vascular bundles in the internodes of $B$. balcooa culm consist of one or two protoxylem elements, two large metaxylem vessels and phloem. There are a few layers of thick-walled sclerenchymatous cells surrounding the metaxylem vessels and two isolated fiber caps (sheaths) located at the phloem and the protoxylem side. This is referred to as the "double broken-waist type" (Figs. 1A, 1B; Liese, 1987). It is often combined with the "broken-waist type" of vascular bundle, where the fiber sheath at the protoxylem side is usually smaller than the other, or even absent (Fig. 1A). 

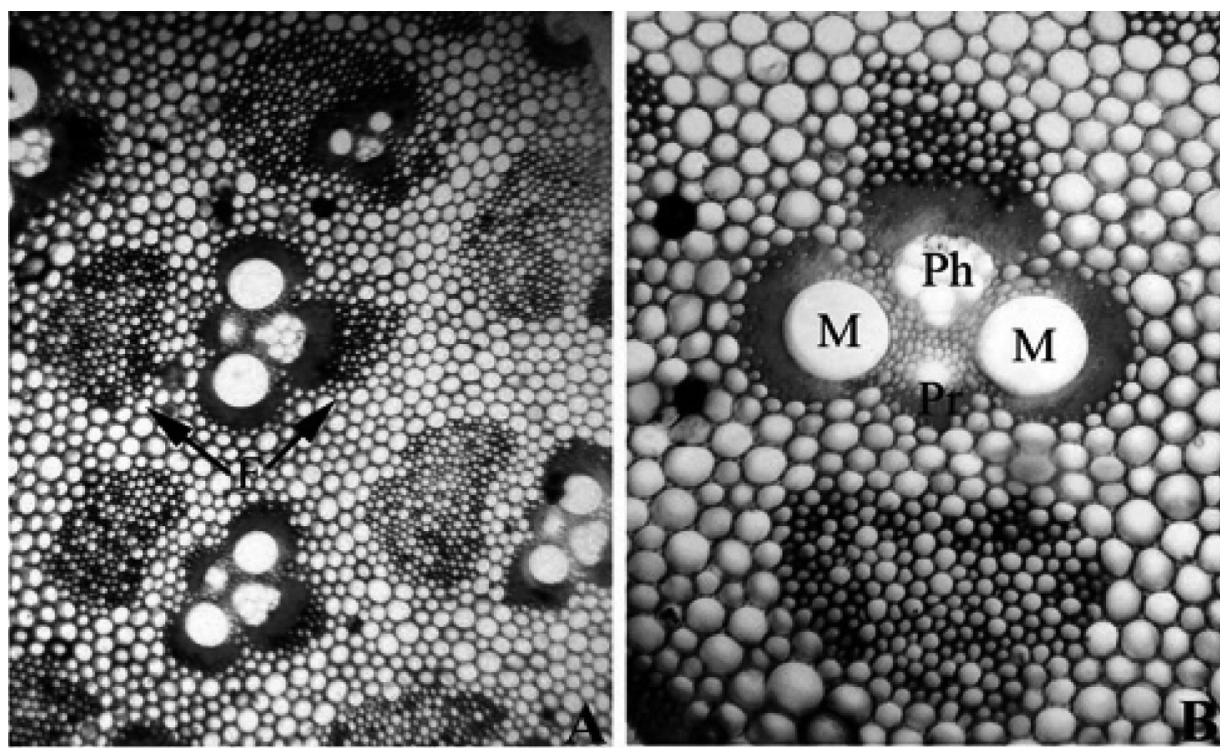

Figure 1. Culm anatomy of B. balcooa, showing "double broken-waist type" vascular bundles intermingled with those of "broken-waist type." The fiber sheath is present only at the protoxylem side (A). F, discrete fiber bundle; M, metaxylem; Ph, phloem and Pr, protoxylem of a "double broken-waist type" vascular bundle are marked (B). (A color version of this figure is available at afs-journal.org.)

\subsection{Physical characteristics of B. balcooa fiber}

The standardized maceration technique was useful for isolating intact, individual fibers from internodal tissues of secondary branches of adult bamboo culms. Derived slenderness ratios of isolated fibers from accessions of locations 3 and 4 were found to be higher ( 243.93 and 212.99 , respectively) than those of other locations; meanwhile, the Runkel ratios were lowest in accessions of locations $3(0.69)$ and $4(0.80)$ and highest in location 5 (1.05) (Fig. 2). The highest flexibility coefficients were found in fibers isolated from accessions of locations 3 (60.00), 4 (57.24) and 11 (57.14) of B. balcooa (Fig. 2). The slenderness ratio or felting power is the physical indicator for fiber durability (Rydholm, 1965). Fibers with enhanced slenderness ratios are more durable. Fibers with lower Runkel ratios $(<1.0)$ are preferred for making quality products (Saikia et al., 1997). The data indicate that except for accessions of locations 2 and 5, all other accessions yielded fibers with acceptable Runkel ratios. The flexibility coefficient was highest in accessions of location 3, 4 and 11 (Fig. 2). The magnitude of fiber strength is usually proportional to this parameter. Interestingly, there are significant variations in physical fiber parameters within this species according to habitat. Evaluation of the three key physical traits indicates that the accessions of location 3 (closely followed by location 4) harbor fibers with the best physical characteristics.

Most woody tropical bamboos are hexaploid, including B. balcooa, in contrast to temperate bamboos, which are tetraploid. In cotton, allotetraploids produce higher quality fibers than the descendent diploid species (Lee et al., 2007). It is possible that polyploid woody bamboos were selected in nature for having higher fiber strength compared to the diploid progenitors, which are perhaps extinct or on the verge of extinction.

\subsection{Chemical characteristics of B. balcooa fiber}

The principal cell wall material of fiber is cellulose; however, hard fibers of bamboo contain a high proportion of lignin in addition to cellulose. The $\alpha$-cellulose content was highest in accessions of locations $3(66.25 \% \mathrm{dw})$ and $4(64.53 \% \mathrm{dw})$ and lowest in accessions of location $2(51.72 \% \mathrm{dw})$. Lignin contents were relatively higher in accessions of locations 5 $(27.93 \% \mathrm{dw}), 6(27.60 \% \mathrm{dw})$ and $7(27.83 \% \mathrm{dw})$ of B. balcooa (Fig. 3) and lowest in accessions of locations $4(17.97 \% \mathrm{dw})$ and $3(20.23 \% \mathrm{dw})$. Total $\alpha$-cellulose content was estimated spectrophotometrically by comparing samples with standards.

It has been shown that non-wood sources could be pulped in one-third of the time required to pulp their woody counterparts due to their lower lignin contents (Ververis et al., 2004). Lignin needs to be extracted from pulp by expensive and environmentally hazardous processes that require large amounts of energy and chemicals for downstream processing. Consequently, it would be beneficial to process low-lignin source materials for the paper industry. Hence, low-lignin raw materials that require less hazardous processing chemicals and have effective production costs are ideal for paper-pulp industries. By contrast, a higher lignin content ensures enhanced culm strength. The presence of lignin confers mechanical strength to the vascular tissue and contributes to waterproofing of the conductive elements, thus ensuring proper fluid transport (Xu et al., 2006).

The correlated physical and chemical characteristics of fibers derived from accessions of locations 3 and 4 unambiguously demonstrated superior fiber trait qualities. Genotypes 


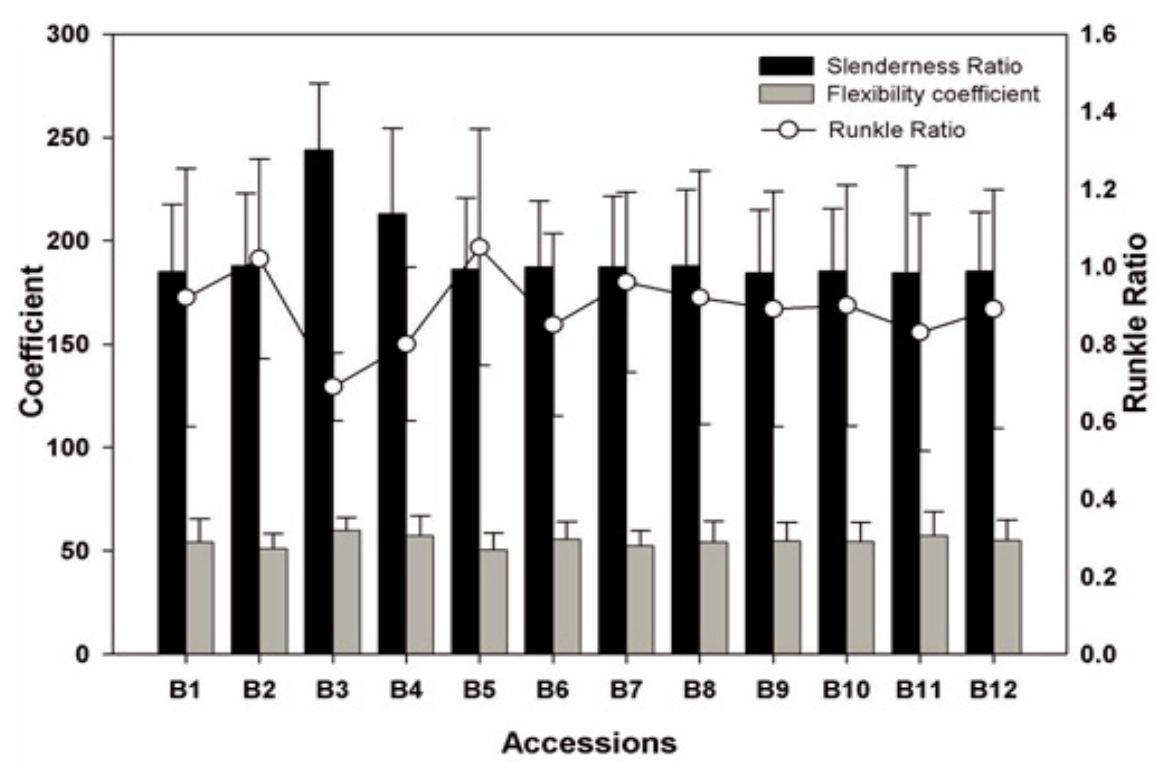

Figure 2. Variations in slenderness ratios (value in Y1 axis, left), flexibility coefficients (Y1 axis) and Runkel ratios (Y2 axis, right) among representative accessions of $B$. balcooa from 12 locations. The data shown are average values, with standard error from the mean ( \pm SEM) indicated as an uncertainty bar.

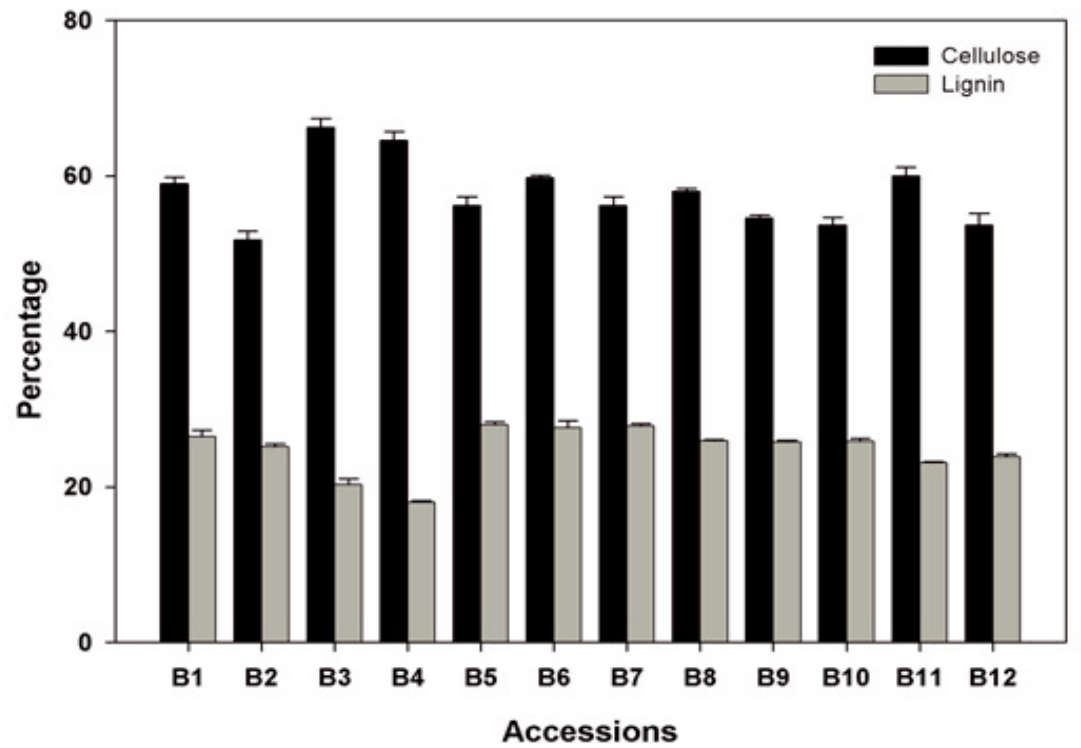

Figure 3. Bar diagram illustrating mean $\%$ dry weights of $\alpha$-cellulose contents and acid-insoluble Klason lignin contents of mature fibers among representative accessions of $B$. balcooa from 12 locations. The data shown are average values, with standard error from the mean $( \pm$ SEM) indicated as an uncertainty bar. 
endowed with high cellulose contents could be used efficiently for high-quality paper-pulp production, and highlignin-containing genotypes could potentially be used as a reinforcing material for polymer matrix composites (Ray et al., 2004) and for construction purposes.

\subsection{Probing lignin deposition during fiber development in internode maturity}

Anatomical changes concomitant with fiber sheath development were studied in three developmental stages of internodes during the maturation of B. balcooa secondary branches, based on CLSM data (Figs. 4A-4D). Stage I represents the 2nd internodal section, which is comparatively young, lignification of fiber cells was initiated, sclerenchymatous cells surrounding proto and metaxylems were autofluorescent, emitting blue fluorescence at 440-460 $\mathrm{nm}$ wavelength after excitation at $405 \mathrm{~nm}$ (Fig. 4A). Lignification was much higher at the 5th internodal sections (Fig. 4, Stage III). Autofluorescence of lignified cell walls has been reported previously, and the intensity was visually detected as being higher than the fiber cells (Fergus and Goring, 1970a; 1970b). Distinct molecular species within the lignin polymer, such as phenylcoumarone and stilbene structures, were considered to be the sources of lignin fluorescence (Albinsson et al., 1999).

Lignin deposition occurs at the final stages of xylem cell differentiation and in the case of dicotyledonous plants, it takes place during secondary thickening of the cell wall (Donaldson et al., 2001). By contrast, in graminaceous monocotyledons, lignin incorporates significant amounts of hydroxycinammate esters at the early stages of lignification. Of these, ferulate-polysaccharide esters and minor amounts of $p$-coumarate analogs are deposited rapidly (Boerjan et al., 2003). It is now well established that CLSM detects laserinduced lignin fluorescence from diverse cellular components (Barsberg and Nielsen, 2003; Donaldson et al., 2001). Cell wall-bound ferulic acids emit blue-green fluorescence in graminaceous monocots and other plants (Harris and Hartley, 1976; Lichtenthaler and Schweiger, 1988; Schmitz et al., 1996), while fluorescence in the xylem vessel wall is due to the presence of lignin (Schmitz et al., 1996).

When the same sections were excited at $458 \mathrm{~nm}$ with an Argon laser or a 405-nm blue diode laser and emissions were collected at 640-700 nm, strong red autofluorescence of chlorophyll was evident in non-fibrous-parenchymatous cells, demarcating the fiber bundles (Fig. 4B, Stages I-III). Chlorophyll fluorescence increased along with the maturation of internodes. An association between an increase in size of fiber bundles and internode maturation was also evident in bright field (Fig. 4C) and superimposed images (Fig. 4D). In general, lignin deposition is higher in the middle lamella and cell corners than in fiber cell walls (Baucher et al., 1998; Saka and Goring, 1985). However, because it occupies a larger portion of the fiber cells, higher lignin content was found in fiber sheaths than in xylems. This finding suggests that CLSMbased autofluorescence could be used as a fiber developmental stage selection marker for analogous molecular investigations.

\subsection{Cellulose estimation by a non-invasive method}

Comparative values of cellulose contents among different accessions of $B$. balcooa were estimated by a non-invasive method, CR labeling and fluorescence measurement using CLSM. CR, a fluorescent dye, is well known for binding specifically to cellulose fibrils. The fluorophore binds to $\beta$ $1-4$, glucans, and staining is strongly dichroic (Verbelen and Kerstens, 2000; Wood, 1980). Cellulose deposition starts at the corners of parenchymatous pith cells and middle lamellar regions of sclerenchymatous cells. Fluorescence emissions of CR-labeled fiber bundles of internodal regions were quantified by CLSM. Fluorescence intensities of fiber bundles collected from all locations were less than those of the accessions from locations 3 and 4 (Supplementary ${ }^{1}$ Fig. S1 and Fig. 5). This finding demonstrated the presence of comparatively higher fluorescence intensity in high-cellulose-containing accessions. This finding further confirms the proposition that CR specifically labels cellulose fibrils, in agreement with previous observations (Verbelen and Kerstens, 2000). Pearson's correlation coefficient between fluorescence values obtained across samples is supported by the data obtained from biochemical analyses $(0.936, P \leqslant 0.01)$, which suggests good agreement between the two methods (invasive vs. non-invasive) of cellulose estimation in bamboo fiber (Fig. 5).

\subsection{Lignin estimation by a non-invasive method}

Here, we report a rapid method of comparative lignin estimation based on orthochromatic labeling by $\mathrm{AO}(\mathrm{Li}$ and Reeve, 2005). AO usually fluoresces at two distinct wavelengths after excitation, a phenomenon is known as metachromasia. AO forms dimers or polymers when combine with lignin as a substrate (Rost, 1992). At higher concentrations, $\mathrm{AO}$ induces self-quenching. We optimized the orthochromatic labeling of $\mathrm{AO}$ by standardizing the effective concentration of $\mathrm{AO}$ as well as the time of exposure to the fluorochrome (Supplementary ${ }^{1}$ Fig. S2). Metachromatic labeling for semiquantitative analysis has been discouraged previously (Li and Reeve, 2005). Emission of green fluorescence of AO-labeled fiber bundles from internodal transverse sections and isolated fibers was measured by LAS AF software and was found to be higher in accessions from locations 5, 6 and 7, while accessions from locations 3 and 4 had the lowest estimated fluorescence levels (Supplementary ${ }^{1}$ Fig. S3 and Fig. 5). Acridine orange has been used widely to assess wood pulp lignification ( $\mathrm{Li}$ and Reeve, 2005) and has recently been used to probe lignin biosynthesis in cell suspension cultures of Ginkgo biloba (Uzala et al., 2009).

Fluorescence emissions of AO-labeled fibers (data not shown) and those of fiber bundles of internodal regions were quantified by CLSM. The lowest fluorescence intensities of isolated fibers and fiber bundles were found for accessions of locations 3 and 4 (Supplementary ${ }^{1}$ Fig. S3 and Fig. 5). This

\footnotetext{
${ }^{1}$ Supplementary material available online only at www.afs-journal. org.
} 

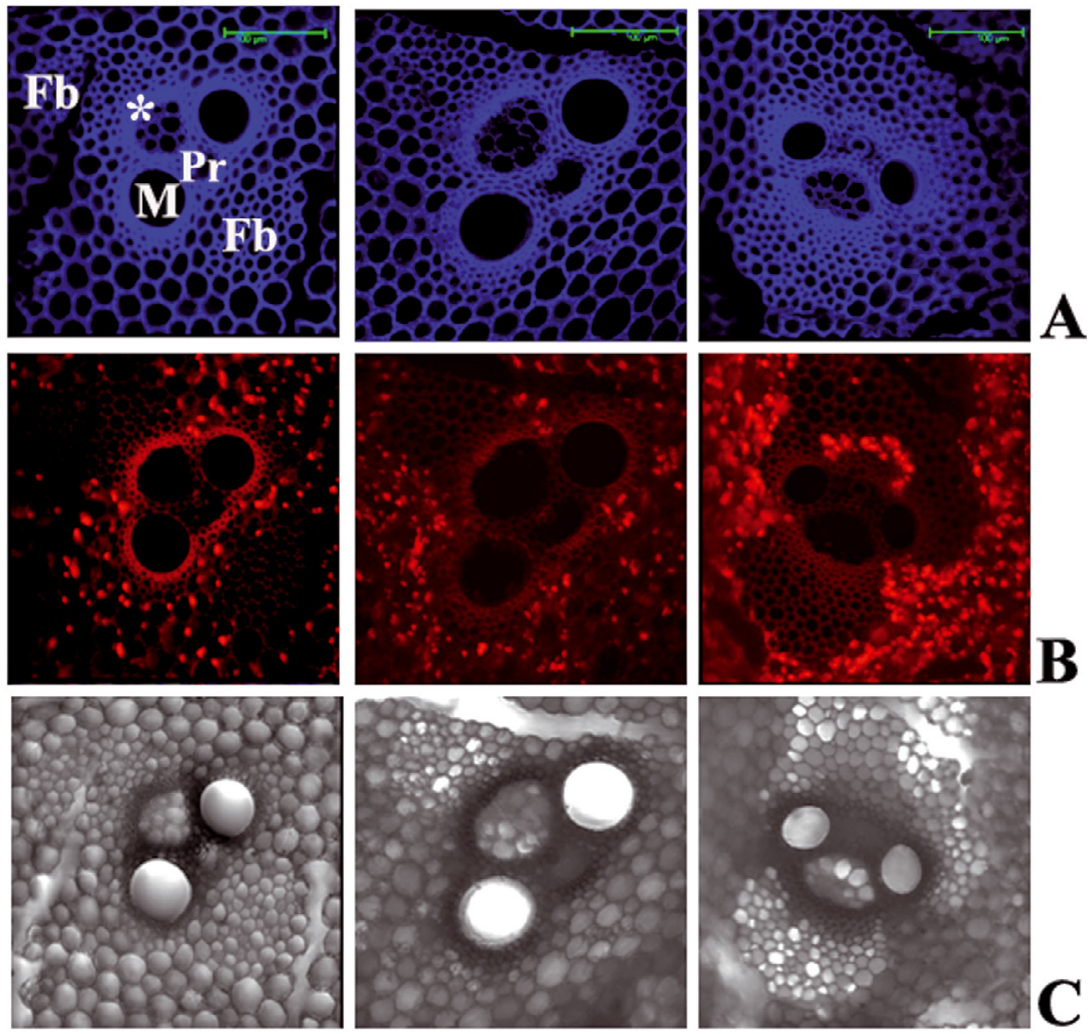

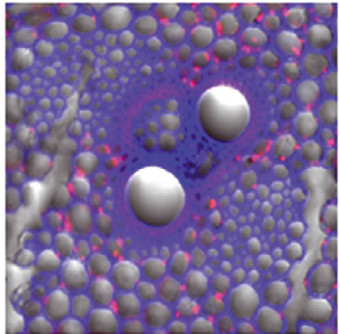

Stage I

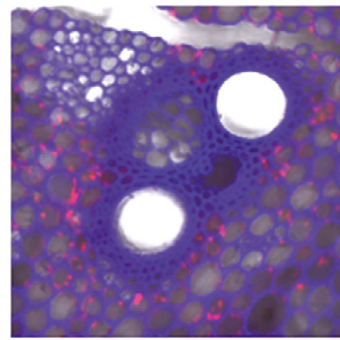

Stage II

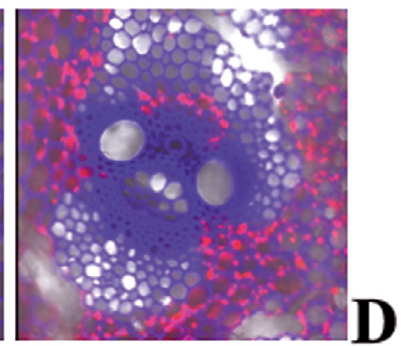

Stage III

Figure 4. CLSM images of transverse sections through internodes of B. balcooa at different stages of fiber development: Stage I. Comparatively young 2nd internodal section, fiber bundle formation initiated. Stage II. Lignification is much higher at the 4th internodal section. Stage III. Fully developed fiber sheaths at the 5th internodal section. A. Lignin and other cell wall components such as ferulic acid, a precursor of lignin, autofluoresced upon excitation at $405 \mathrm{~nm}$, images acquired at 440-460-nm range. B. Chlorophyll autofluorescence in non-fibrous parenchymatous cells outside vascular and fiber bundles (excitation $458 \mathrm{~nm}$, emissions at 640-700 nm). C. Same sections under bright field, showing vascular bundle with $\mathrm{Fb}$ (fiber bundle), M, metaxylem; Pr, protoxylem and * for phloem. D. Confocal images acquired in A (blue fluorescence) and B (red fluorescence) were overlaid on the bright field image. (A color version of this figure is available at www.afs-journal. org.)

finding demonstrated the presence of comparatively higher fluorescence in high-lignin-containing accessions, as AO specifically labels lignin molecules ( $\mathrm{Li}$ and Reeve, 2005). The fluorescent data are also in agreement with the data obtained from biochemical analyses (Fig. 5).

\section{CONCLUSIONS}

Here, we have established a useful method for evaluating fiber quality in a non-wood plant species. A number of industrially important fiber qualities were found in the wild germplasms of B. balcooa. This investigation also describes the utility of CLSM-based information to identify defined stages of fiber development in bamboo. Our study lays the groundwork for future research that will utilize similar CLSM-based approaches to rapidly and efficiently screen wild germplasms of other non-wood resources.

Acknowledgements: Authors are grateful to the Directors of Institute of Life Sciences and Bose Institute for providing research 


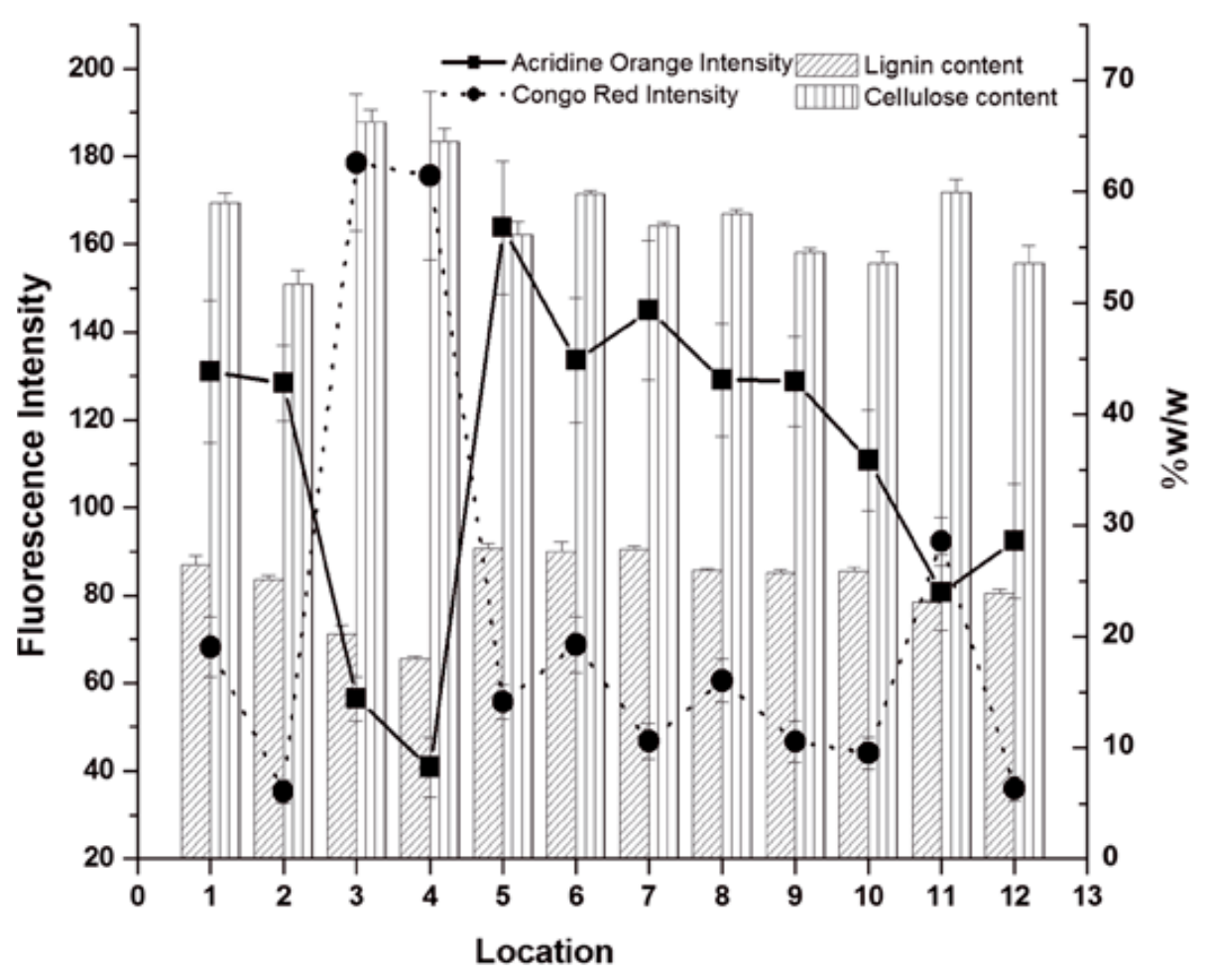

Figure 5. Comparative histogram showing biochemical estimation of $\alpha$-cellulose and Klason lignin contents among representative accessions of $B$. balcooa from 12 locations (represented as 1 to 12, see Table I for details of geographical locations); gram \% (w/w) values are represented on the Y-2 axis, and error bars represent \pm SD values. Arbitrary units of fluorescence intensities for Congo red-labeled $\alpha$-cellulose and acridine orange-labeled lignin of fiber bundles are represented on the Y-1 axis and plotted as a line with data points.

facilities. We thank an anonymous reviewer for his/her helpful comments to improve the quality of the CLSM-based work. Financial assistance from the Department of Biotechnology, Government of India (BT/PR-5998/INF/22/028/2005) and from the Department of Science and Technology, (SR/SO/PS-79/07) New-Delhi, India are thankfully acknowledged. JSG and SB are thankful to the Council of Scientific and Industrial Research, New Delhi, India for the fellowships under project (1062)/03/EMR-II and NET / CSIR, respectively.

\section{REFERENCES}

Albinsson B., Li S., Lundquist K. and Stomberg R., 1999. The origin of lignin fluorescence. J. Mol. Struct. 508: 19-27.

ASTM (American Society for Testing and Materials), 1996. Standard methods of evaluating the properties of wood based fiber and particle panel materials. ASTM D 1106-96. Philadelphia, USA.

Barsberg S. and Nielsen K.A., 2003. Oxidative quenching of spruce thermo-mechanical pulp fiber autofluorescence monitored in real time by confocal laser scanning microscopy-implications for lignin autofluorescence. Biomacromolecules 4: 64-69.

Baucher M., Monties B., Van Montagu M. and Boerjan W., 1998. Biosynthesis and genetic engineering of lignin. Crit. Rev. Plant Sci. 17: 125-197.

Boerjan W., Ralph J. and Baucher M., 2003. Lignin biosynthesis. Ann. Rev. Plant Biol. 54: 519-546.

Das M., Bhattacharya S. and Pal A., 2005. Generation and characterization of SCARs by cloning and sequencing of RAPD products: A strategy for species-specific marker development in bamboo. Ann. Bot. 95: 835-841.
Donaldson L.A, Hague J. and Snell R., 2001. Lignin distribution in coppice poplar, linseed and wheat straw. Horzforschung 55: 379-385.

Espiloy Z.B., 1987. Effect of age on the physico-mechanical properties of some Philippine bamboo. In: Rao A.N., Dhanarajan G. and Sastry C.B. (Eds.), Recent Research on Bamboo. Proc. Intern. Workshop Hangzhou, China, Singapore, pp. 244-246.

FAO. 1997. Provisional outlook for global forest products consumption, production and trade. Forestry Department, Policy and Planning Division, FAO, Rome.

Fergus B.J. and Goring D.A.I., 1970a. The location of guaiacyl and syringyl lignins in birch xylem tissue. Holzforschung 24: 113-117.

Fergus B.J. and Goring D.A.I., 1970b. The distribution of lignin in birch as determined by ultraviolet microscopy. Holzforschung 24: 118124.

Ganapathy P.M. 1997. Sources of non wood fiber for paper, board and panels production: status, trends and prospects for India. In: Asiapacific forestry sector outlook study working paper series, Working Paper No. APFSOS/WP/10. Forestry Policy and Planning Division, Rome Regional Office for Asia and the Pacific, Bangkok, pp. 1-59.

Harris P.J. and Hartley R.D., 1976. Detection of bound ferulic acid in cell walls of the Gramineae by ultraviolet fluorescence microscopy. Nature 259: 508-510.

Hommel M., Khalil-Ahmad Q., Jaimes-Miranda F., Mila I., Pouzet C., Latche A., Pech J.C., Bouzayen M. and Regad F., 2008. Overexpression of a chimeric gene of the transcriptional co-activator MBF1 fused to the EAR repressor motif causes developmental alteration in Arabidopsis and tomato. Plant Sci. 175: 168-177.

Lee J.J., Woodward A.W. and Chen Z.J., 2007. Gene expression changes and early events in cotton fiber development. Ann. Bot. 100: 13911401. 
Li K. and Reeve D.W., 2005. Fluorescent Labeling of Lignin in the Wood Pulp Fiber Wall. J. Wood Chem. Technol. 24: 169-181.

Lichtenthaler H.K. and Schweiger J., 1998. Cell wall bound ferulic acid, the major substance of the blue-green fluorescence emission of plants. J. Plant Physiol. 152: 272-282.

Liese W., 1987. Anatomy and properties of bamboo. In Recent Research on Bamboos. In: Rao A.N., Dhanarajan G. and Sastry C.B. (Eds.). Chinese Academy of Forestry, Peking, China and International Development Research Centre, Canada, pp. 196-208.

Liese W., 1992. The structure of bamboo in relation to its properties and utilization. In: Bamboo and its use, Proceedings International Symposium on Industrial use of bamboo, Beijing, China, 7th to 11th December, 1992. Intern. Trop. Timber Organization, Chinese Academy of Forestry, China.

Ogbonnaya C.I., Roy-Macauley H., Nwalozie M.C. and Annerose D.J.M., 1997. Physical and histochemical properties of kenaf (Hibiscus cannabinus L.) grown under water deficit on a sandy soil. Indus. Crops Prod. 7: 79-81.

Parameswaran N. and Liese W., 1976. On the fine structure of bamboo fibers. Wood Sci. Tech. 10: 231-246.

Ray A.K., Das S.K. and Mondal S., 2004. Microstructural characterization of bamboo. J. Mat. Sci. 39: 1055-1066.

Rost F.W.D., 1992. Fluorescence microscopy, Cambridge University Press, Cambridge, 253 p.

Rydholm R.A., 1965. Pulping processes, Interscience Publishers, New York, $93 \mathrm{~J} . \mathrm{V}$.

Saikia S.N., Goswami T. and Ali F., 1997. Evaluation of pulp and paper making characteristics of certain fast growing plants. Wood Sci. Tech. 31: 467-475.
Saka S. and Goring D.A.I., 1985. Localization of lignins in wood cell walls. In: Higuchi T. (Ed.), Biosynthesis and biodegradation of wood components, Academic, Orlando, pp. 51-62.

Schmitz R., Reuber S., Veit M. and Weissenbock G., 1996. Comparison of soluble and insoluble hydroxycinnamic acids (HCAs) with soluble flavonoids with regard to UV protection of rye primary leaves. Plant Physiol. Biochem. Special Issue, 10th FESPP Congress, Florence, pp. 309-310.

Updegraff D.M., 1969. Semimicro determination of cellulose in biological materials. Ann. Biochem. 32: 420-424.

Uzala, E. N., Go' mez Rosb L.V., Pomara F., Bernala. M. A., Paradelac, A., Albarc, J. P. and Ros Barcelo, A., 2009. The presence of sinapyl lignin in Ginkgo biloba cell cultures changes our views of the evolution of lignin biosynthesis. Physiol. Plant. 135: 196-213.

Verbelen J.-P. and Kerstens S., 2000. Polarization confocal microscopy and Congo Red fluorescence: a simple and rapid method to determine the mean cellulose fibril orientation in plants. J. Microscopy 198: 101-107.

Ververis C., Georghiou K., Christodoulakis N., Santas P. and Santas R., 2004. Fiber dimensions, lignin and cellulose content of various plant materials and their suitability for paper production. Indus. Crops Prod. 19: 245-254.

Widjaja E.A. and Risyad Z., 1987. Anatomical properties of some bamboo utilized in Indonesia. In: Rao A.N., Dhanarajan G. and Sastry C.B. (Eds.), Recent Research on Bamboo. Proc. Intern. Workshop Hangzhou, China, Singapore, pp. 244-246.

Wood, P.J., 1980. Specificity in the interaction of direct dyes with polysaccharides. Carbohydr. Res. 85: 271-287.

Xu F., Zhonga X.C., Sunb R.C. and Luc Q., 2006. Anatomy, ultrastructure and lignin distribution in cell wall of Caragana korshinskii. Indus. Crops Prod. 24: 186-193. 


\section{Online Material}



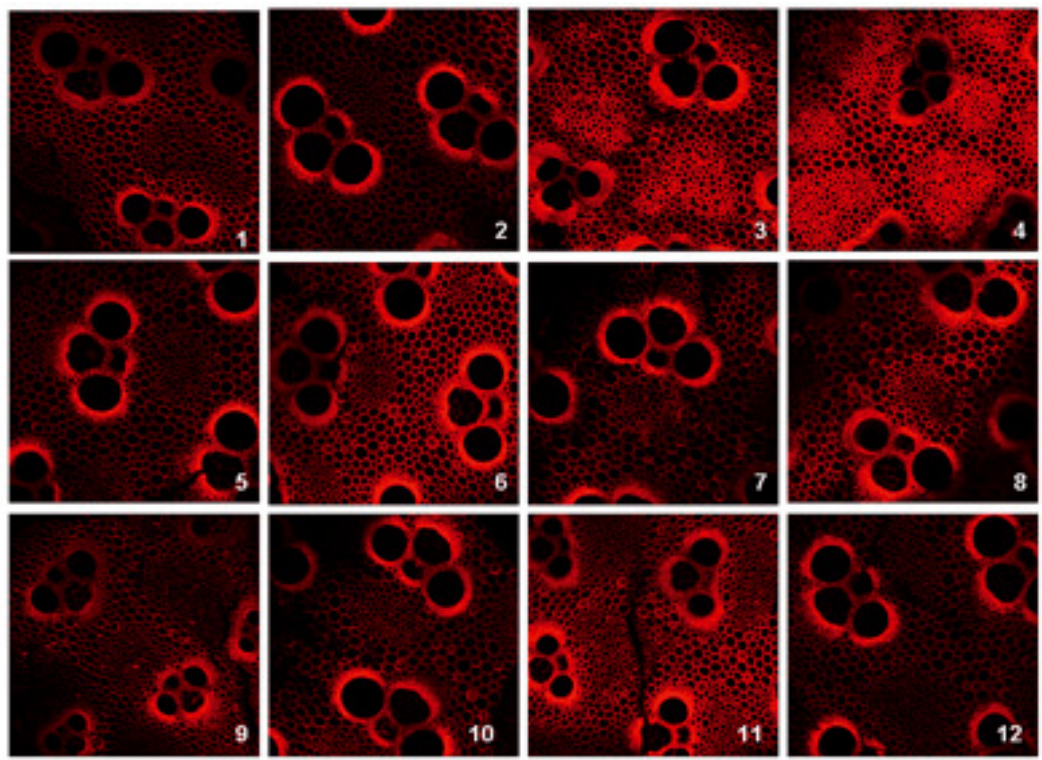

Supplementary Figure S1. Congo red (CR)-labeled fluorochromic signals in transverse sections of internodal regions acquired by CLSM from representative accessions of $B$. balcooa from 12 locations (represented as 1 to 12, see Tab. I for details of geographical locations).
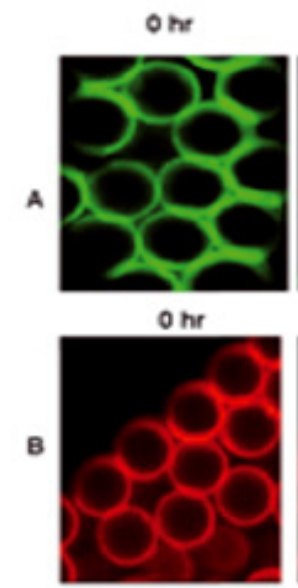

$1 / 2 \mathrm{hr}$

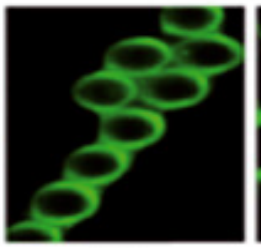

$1.2 \mathrm{hr}$

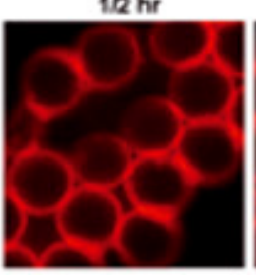

thr

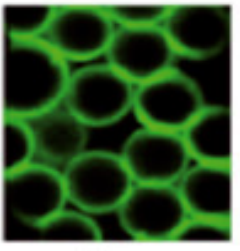

1 the

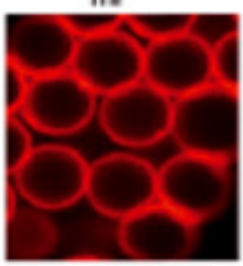

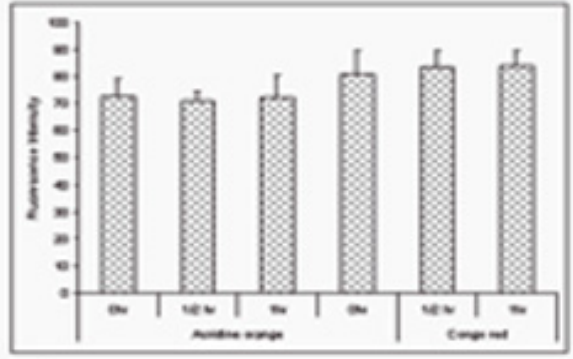

c

Supplementary Figure S2. Images of fluorescent beads at different time intervals, used as internal controls for AO-stained samples (A) and CR-stained images (B). Graphical representation of the fluorescence intensity values of CR- and AO-stained beads acquired by CLSM during the experimental period, showing consistency. Images of fluorescent beads and fluorescence intensity values depict the stability of laser illumination during the image acquisition period. 

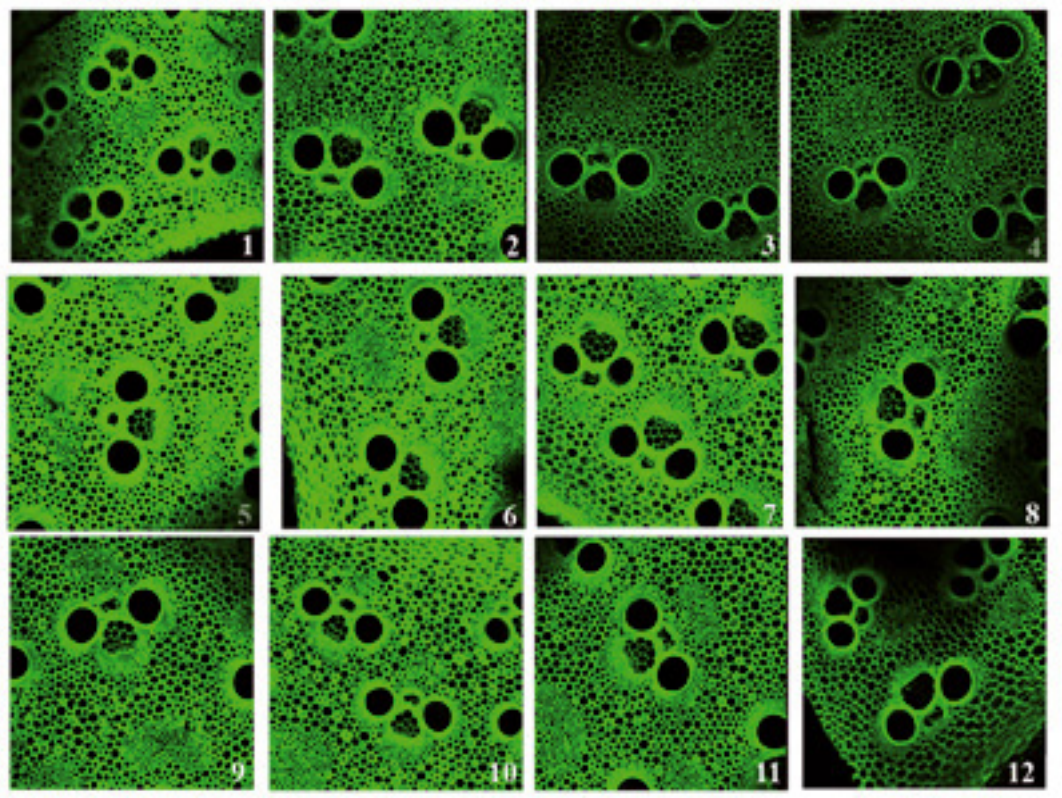

Supplementary Figure S3. Acridine orange-labeled fluorescence images acquired by CLSM of transverse sections of internodal regions from representative accessions of $B$. balcooa collected from 12 different locations (represented as 1 to 12 , see Tab. I for details of geographical locations). 